A vibrotactile learning experiment was conducted for two small groups: one of sighted, and one of blind Ss. Vibrators, of the Sherrick type, were placed at five body loci. These loci are thought not to have been previously described in this type of experiment. A modification of the Howell system was used for encoding signals. There were no significant differences between the amounts of information transmitted in the two groups.

The skin as a recelver and converter of various forms of energy has been studied intensively for a number of years. In the last 10-15 years there has been an increasing amount of research devoted to cutaneous sensitivity, and particular attention has been given to the problems of communication through the skdn.

Gilmer (1966) has described a variety of approaches to the study of the cutaneous modality, and there have been some recent studies dealing spectifcally with aspects of cutaneous communication. Despite the increased investigation, Bliss \& Crane (1965) stated that "Apart from its use by the visually handicapped, the tactile system has not generally received serious consideration as a method of communication." One aspect of cutaneous communication which requires more intensive investigation is the learning process.

Vibrotactile experiments concerned with coded signals are rarely reported in the literature, and it is more than 10 years since the first of these was reported by Howell (1956) and Geldard (1957). The present investigation was made in order to replicate part of Howell's work, and by modifying his system, to attempt to demonstrate whether differences of vibrotactile learning could be shown between sighted and blind Ss.

Subjects

The sighted Ss were four adults (three males and one female). There were two male and two female blind adults, all of whom were experienced Braille readers. Each $\mathbf{S}$ was tested individually.

\section{Apperatus and Precedure}

Five Sherrick-type vibrators were used to transduce signals. They were connected to a portable 40-element signalling unit. The latter consisted of a transformer and pushbutton switches. For convenience, the switches were mounted in console fashion on the top of the unit. The transformer received its input from domestic line current $(240 \mathrm{~V})$ and was tapped to give three electrical intensities, $10 \mathrm{~V}, 15 \mathrm{~V}$, and $20 \mathrm{~V}$. It was not possible to transmit signals having the three durations described by Howell (1956). The apparatus had been designed to transmit single, double, and treble pulses and the "vibratese" code described by Howell was modified accordingly.
$S$ sat in a normal comfortable position either at a table or in a chair with arm rests at distances between $6 \mathrm{ft}$ and $35 \mathrm{ft}$ from $\mathrm{E}$, depending on the size of the room avallable. The vibrators were attached to the skin by elastlc belting and anap fasteners at each of five posiHons: left and right forearms, left and right biceps, and the outside of the right thigh at a point 6 in. above the knee. $S$ sat at right angles to $\mathrm{E}$ and could not observe the console of the signalling apparatus. The signals could not be seen or heard.

All So were given 15 trials. A trial consisted of the vibratory equivalent of the letters of the alphabet in random order. Fifteen of the signals were single pulses, 11 were double pulses. Each "letter' had a duration of 1 sec, 1.e., single pulses lasted for $1 \mathrm{sec}$ and double pulses totalled 1 sec. Identical instructions were given to all Ss.

Masking noise was provided by an exhaust fan. E described the procedure, demonstrated all of the signals one at a time and in sequence, and then repeated four sample letters. Lists of stimuli were randomly selected. Each S recelved a signal after a verbal warning from the $E$, and was then required to identify the intensity of the sigmal at the particular vibrator being energized. The $\mathrm{E}$ then named the intensity and repeated the signal, and the $S$ responded by identifying the letter. The correct signal was again announced by the $E$ and its vibratory equivalent once more signalled. There was no fixed interstimulus interval, but there was a pause of approximately $5 \mathrm{sec}$ between the final repetition of one signal and the onset of the next. Four to five trials were given per session.

\section{Results and Discussion}

The mean percentages of correct responses for each $S$ have been plotted against trials in Fig. 1. Individual performances were very similar to those reported by Howell (1956) and Geldard (1957) although conditions differed between the early experiments and the present investigation. Howell used a different type of vibrator; Ss lay on their backs and had the flve vibrators attached to the skin covering the ventral thorax-a bony rather than a fleshy body area-which may have resulted in the transmission of sigmals to the cochlea by bone conduction. A vibration engineering study on the five Sherrick-type vibrators showed that calculated amplitudes of vibration at three frequencies ranged from $0.04 \mu$ to $29.0 \mu$. These amplitudes were obtained when vibrators were rigidly clamped and the values were considerably lower than those described by Howell. Training schedules lasted for approximately 3 h. A large proportion of the learning task was achleved in this time, 1.e., most of the early learning was accom- 


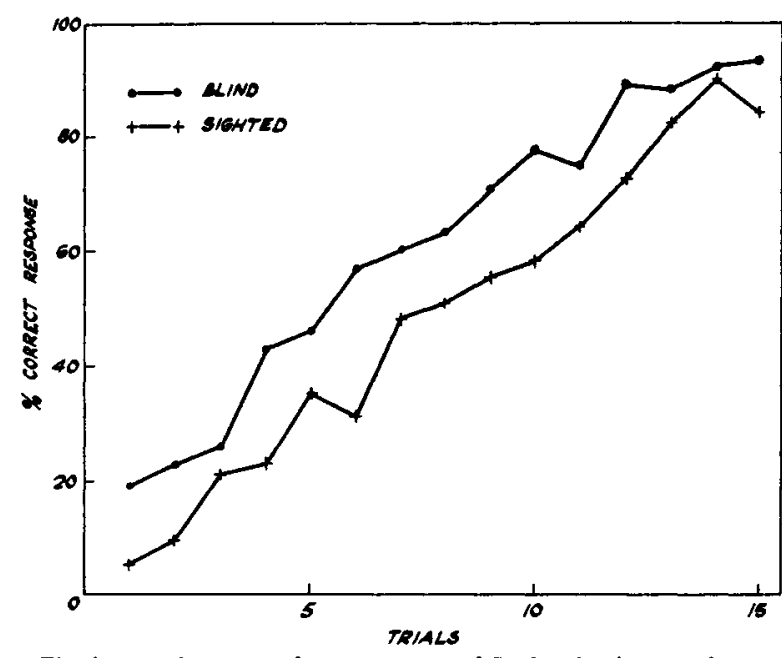

Fig. 1. Learning curves for two groups of Ss showing increase in proficiency of reception as a function of practice (intensity cues). Mean responses have been plotted for each group.

plished after 2-3 h of practice. The stimulus and response frequencies for the two groups of Ss were studied and the information transfers for the first five and second five trials were computed. Tests of significance ( $t$ test) were made between the groups (values of
$\hat{T}_{(x ; y)}$ in bits). There were no significant differences between the two groups.

Accuracy of $100 \%$ was rare, although one-third of the responses achieved an accuracy of $80 \%$ or greater. The best individual performance was by $a$ blind $S$. Two-thirds of her responses reached an accuracy of $90 \%$ or better, and in six of the trials, $100 \%$ accuracy was obtained. Most Ss made the same types of errors and the most frequent of these were always errors of intensity. This confirms a finding of Howell. Although conditions, apparatus, and technique were dissimilar, the data suggest that the system described by Howell warrants fuller investigation, and the slightly superior performance of blind Ss might be significant if larger groups of Ss could be studied.

\section{References}

BLISS, J. C., \& CRANE, H. C. Experiments in tactual perception. NASA Contractor Report CR-322, Stanford Research Institute, 1965.

GELDARD, F. A. Adventures in tactile literacy. Amer. Psychol, 1957, $12,115-124$.

GILMER, B. von HALLER. Problems in cutaneous communication from psychophysics to information processing. The American Foundation for the Blind, New York, 1966.

HOWELL, W. C. Training on a vibratory communication system. Unpublished Master's thesis, University of Virginia, 1956.

SHERRICK, C. E. Simple electromechanical vibration transducer. Rev. Sci. Instrum, 1965, 36, 1893-1894. 